\title{
Research article \\ Presence of hemophagocytes in bone marrow- A study in a tertiary care center in South India
}

\author{
Gowsik Kanimozhi ${ }^{1}$, Priyathersini Nagarajan ${ }^{2}$, Sri Gayathri ${ }^{2}$, Mohan Arthi $^{3}$ \\ ${ }^{1}$ Assistant Professor, Department of Pathology, Aarupadai veedu medical college, Puducherry, India \\ ${ }^{2}$ Associate Professor, ${ }^{3}$ Assistant Professor, Department of Pathology, Sri Ramachandra Institute of Higher education and \\ Research, Chennai, Tamil Nadu, India
}

(Received: December $2020 \quad$ Revised: August $2021 \quad$ Accepted: September 2021)

Corresponding author: N. Priyathersini. E mail: priyathersinin@ sriramachandra.edu.in

\begin{abstract}
Introduction and Aim: Haemophagocytic Lymphohistiocytic Syndrome (HLH) is a fatal disease with characteristic proliferation of histiocytes in the organs including bone marrow, liver, spleen, kidney, csf, meninges, lymph nodes and subcutaneous tissue which phagocytes the blood cells. In all unexplained cases of cytopenias, organomegaly and pyrexia of unknown origin the HLH should be thought off. Though there are established criteria to diagnose, early diagnosis can reduce the mortality rate due to HLH. Documenting the haemophagocytes in the biopsy can sometimes be very helpful in arriving at the diagnosis.
\end{abstract}

Materials and Methods: We identified patients who were diagnosed with or suspected to have HLH by bone marrow aspiration or biopsy admitted to Sri Ramachandra Medical College Hospital and Research Institution from January 2010 to June 2017. We retrospectively reviewed patients' medical records that have haemophagocytes in bone marrow aspirations and collected complete clinical history and laboratory findings. Those history included fever, cytopenias, and organomegaly. Their triglyceride levels, ferritin, ESR or any other abnormal elevated lab values were also noted down. If they had any established diagnosis then that was also noted.

Results: This is a descriptive study and the details of the data like clinical history, clinical features, laboratory investigations and abnormal values are represented using tabular column, Pie chart and bar diagrams.

Conclusion: From pathological point of view, documenting each case presenting with Haemophagocytes and looking into the factors like age, significant laboratory values along with clinical features can be a valuable tool to come to a provisional diagnosis and might help the clinician to proceed with the treatment for a life-threatening disease without much delay.

Keywords: Haemophagocyes; histiocytes; bone marrow aspiration.

\section{INTRODUCTION}

$\mathrm{H}$ aemophagocytic Lymphohistiocytic Syndrome (HLH) is a fatal disease leading to end organ damage and death. There is characteristic proliferation of histiocytes in the organs including bone marrow, liver, spleen, kidney, meninges, lymph nodes and subcutaneous tissue which phagocytes the blood cells $(1,2)$ Earlier HLH is classified as primary form and secondary form, the former is genetically mediated and they have abnormal cytotoxic function of NK cell and T cells and the latter form is associated with infections and malignancy. Later the designation was changed to genetic for the primary and acquired for the cases of secondary HLH. All the cases which manifest at childhood does not have any genetic defects and all the cases with genetic defects does not manifest at young age. The basic mechanism is hypercytokinemia which results in end organ damage which in turn leads to death $(1,3)$. In all unexplained cases of cytopenias, organomegaly and pyrexia of unknown origin the HLH should be thought off. Early diagnosis can reduce the mortality rate due to HLH. Documenting the haemophagocytes in the biopsy can sometimes be very helpful in arriving at the diagnosis though we have we established criteria to diagnose $(2,3)$.

\section{MATERIALS AND METHODS}

From patients' medical records we identified patients who were diagnosed with or suspected to have HLH by bone marrow aspiration or biopsy admitted to Sri Ramachandra Medical College Hospital and Research Institution from January 2010 to June 2017. The local institutional review board approved the study. Because the study was based on a review of medical record with clinical details, the requirement for written informed consent was waived.

We retrospectively reviewed cases that have haemophagocytes in bone marrow aspirations and collected complete clinical history and laboratory findings. Those history included fever, cytopenias, and organomegaly. Their triglyceride levels, ferritin, ESR or any other abnormal elevated lab values were also noted down. If they had any established diagnosis then that was also noted. This is a descriptive study and the details of the data like clinical history, clinical features, laboratory 
investigations and abnormal values are represented using tabular column, Pie chart and Bar diagrams.

\section{RESULTS}

Totally eighteen cases (18) out of which 7(39\%) were female patients and remaining $11(61 \%)$ patients were male patients. The age of distribution was more in paediatric age group 13 Patients that is $72 \%$ were less than 15 years, $28 \%$ of cases were adult. Among thirteen patients four $(22 \%)$ patients were less than one year of age. Though seventeen patients (94.4\%) had fever, the clinical diagnosis of pyrexia of unknown origin was the diagnosis for six cases. Three cases were known case of acute lymphoblastic leukaemia. Three cases were systemic disease including SLE with Evan's syndrome, Juvenile arthritis and septic shock. Two cases were childhood MDS. A rare case of Chediak Higashi syndrome (Fig.2) and a known case of Macrophage Activation Syndrome (MAS). One adult patient had prostatic carcinoma metastasis to the bone marrow and one more was a case of malaria, gametocytes seen in bone marrow Fig. 1. The age, gender of the patient, clinical diagnosis, the criteria and other parameter are given in Table 1.

\section{Clinical Diagnosis}
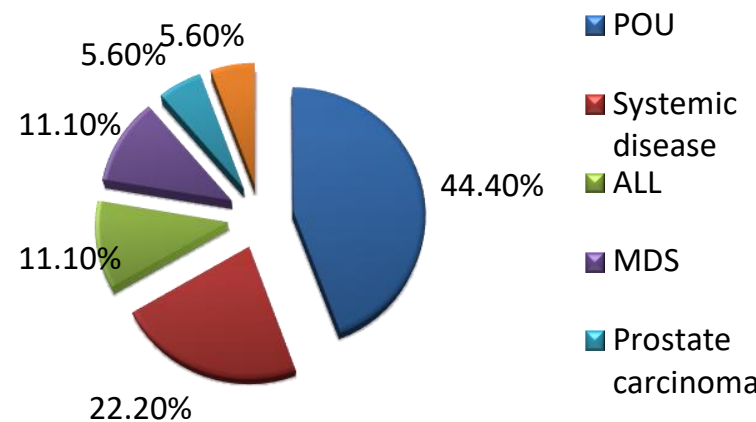

Fig. 1: Clinical diagnosis

Table 1. Patients' Age, gender, clinical diagnosis, clinical features and lab values

\begin{tabular}{|c|c|c|c|c|c|c|c|c|c|}
\hline $\begin{array}{l}\mathrm{Pt} \\
\text { ID }\end{array}$ & Age/Sex & $\begin{array}{c}\text { Clinical } \\
\text { Diagnosis }\end{array}$ & Fever & $\begin{array}{l}\text { Cytopenia } \\
\text { (Pan/ Bi) }\end{array}$ & SM & BMA & $\begin{array}{c}\text { TG level } \\
(<150 \mathrm{mg} / \mathrm{dl})\end{array}$ & $\begin{array}{c}\text { Ferritin } \\
(6-159 \mathrm{ng} / \mathrm{ml})\end{array}$ & $\begin{array}{c}\text { LDH } \\
(<248) \\
\end{array}$ \\
\hline 1. & $24 / F$ & FFE & $\mathrm{Y}$ & Pan & $\mathrm{Y}$ & $\begin{array}{c}\text { Hypo marrow } \\
\text { HLH }\end{array}$ & 242 & $>16,500$ & 576 \\
\hline 2. & $15 / \mathrm{M}$ & FFE & $\mathrm{Y}$ & $\begin{array}{l}\mathrm{Bi}(\mathrm{Hb} \\
\& \mathrm{PLt})\end{array}$ & $\mathrm{Y}$ & $\begin{array}{c}\text { Hypo marrow } \\
\text { HLH }\end{array}$ & 257 & 7721.30 & 1359 \\
\hline 3. & $13 / F$ & PUO & $\mathrm{Y}$ & $\mathrm{Bi}$ & $\mathrm{Y}$ & $\begin{array}{c}\text { Hypo marrow } \\
\text { HLH }\end{array}$ & 187 & 2425.10 & 618 \\
\hline 4. & 21Days/M & FFE & $\mathrm{Y}$ & $\begin{array}{l}\text { Bi (Hb, } \\
\text { PLT) }\end{array}$ & $\mathrm{Y}$ & HLH & 222 & $>16,500$ & 530 \\
\hline 5. & $8 / \mathrm{F}$ & $\begin{array}{c}\text { ALL } \\
\text { relapse }\end{array}$ & $\mathrm{Y}$ & Nil & Nil & $\begin{array}{c}\text { Hypo marrow } \\
\text { HLH }\end{array}$ & UN & UN & UN \\
\hline 6. & 3Months/F & CHS & $\mathrm{Y}$ & $\begin{array}{l}\mathrm{Bi}(\mathrm{Hb}, \\
\text { PLT) }\end{array}$ & $\mathrm{Y}$ & HLH & 363 & 6149.90 & 735 \\
\hline 7. & 23/M & FFE & $\mathrm{Y}$ & Pan & $\mathrm{Y}$ & HLH & 41 & 4.10 & UN \\
\hline 8. & $63 / \mathrm{M}$ & $\begin{array}{l}\text { Prostatic } \\
\text { ca mets } \\
\text { to BM }\end{array}$ & $\mathrm{N}$ & Nil & Nil & $\begin{array}{l}\text { Mets deposit } \\
\text { wit HLH }\end{array}$ & Un & $>16,500$ & 898 \\
\hline 9. & $38 / \mathrm{M}$ & Malaria & $\mathrm{Y}$ & Nil & Nil & $\begin{array}{c}\text { Malaria } \\
\text { gametocyte } \\
\text { HLH }\end{array}$ & 123 & Un & Un \\
\hline 10. & $22 / \mathrm{M}$ & $\begin{array}{l}\mathrm{K} / \mathrm{C} / \mathrm{O} \\
\mathrm{MAS}\end{array}$ & $\mathrm{Y}$ & $\mathrm{Bi}$ & $\mathrm{Y}$ & HLH & 73 & 1058.97 & un \\
\hline 11. & $15 / \mathrm{M}$ & SSS & $\mathrm{Y}$ & $\mathrm{Bi}(\mathrm{Hb}, \mathrm{Plt})$ & $\mathrm{N}$ & HLH & 79 & Un & Un \\
\hline 12 & $15 / \mathrm{Fq}$ & $\begin{array}{l}\text { SLE with } \\
\text { Evan's } \\
\text { syn } \\
\end{array}$ & $\mathrm{Y}$ & Pan & $\mathrm{N}$ & $\begin{array}{l}\text { Hypo marrow } \\
\text { dyEr, HLH }\end{array}$ & 121 & $\begin{array}{c}\text { C3 139, c4 } \\
21.9\end{array}$ & 351 \\
\hline 13 & $\begin{array}{l}\text { 1Month } \\
\text { /Mq }\end{array}$ & FFE & Y & Pan & Y & HLH & 92 & Inc & Inc \\
\hline 14 & $4 / \mathrm{F}$ & JR Ar & $\mathrm{Y}$ & NIl & $\mathrm{Y}$ & $\begin{array}{l}\text { Er hy } \\
\text { MAS }\end{array}$ & 5 & Un & un \\
\hline 15. & $12 / \mathrm{M}$ & $\begin{array}{l}\text { Fever, } \\
\text { MDS }\end{array}$ & Y & BI & $\mathrm{Y}$ & $\begin{array}{l}\text { MDS } \\
\text { HLH } \\
\end{array}$ & 128 & Un & 1162 \\
\hline 16. & $1 / \mathrm{F}$ & $\mathrm{POU}$ & $\mathrm{Y}$ & $\mathrm{Bi}$ & $\mathrm{Y}$ & Dysery HLH & 70 & 257.4 & 1506 \\
\hline 17. & $5 / \mathrm{M}$ & ALL & $\mathrm{Y}$ & Pan & $\mathrm{Y}$ & ALL, HLH & 367 & 6253.80 & 69 \\
\hline 18. & $7 / \mathrm{M}$ & $\begin{array}{c}\text { ITP, } \\
\text { CHMDS }\end{array}$ & $\mathrm{Y}$ & $\mathrm{Bi}(\mathrm{HB}, \mathrm{TC})$ & $\mathrm{Y}$ & HLH & 385 & 7821.80 & 981 \\
\hline
\end{tabular}

PUO- Pyrexia of unknown Origin, Pan- Pancytopenia, Bi- Bicytopenia, Hb- Haemoglobin, TC- Total count, Plt- Platelet, CHS- Chediak- Higashi syndrome, SSS - Septic Shock syndrome, SM- Splenomegaly, BMA- Bone marrow aspiration, TG 
lvel- Triglyceride Level, FFE- Fever for Evaluation, PUO- Pyrexia Unknown origin , MAS- Macrophage activation syndrome, SSS- Septic Shock Syndrome, Hypo Marrow- Hypocellular marrow, SLE- Systemic Lupus erythematosis, JR Ar- Juvenile rheumatoid arthritis, Dy Er- Dyserythropoiesis, ALL- Acute Lymphoblastic Leukaemia

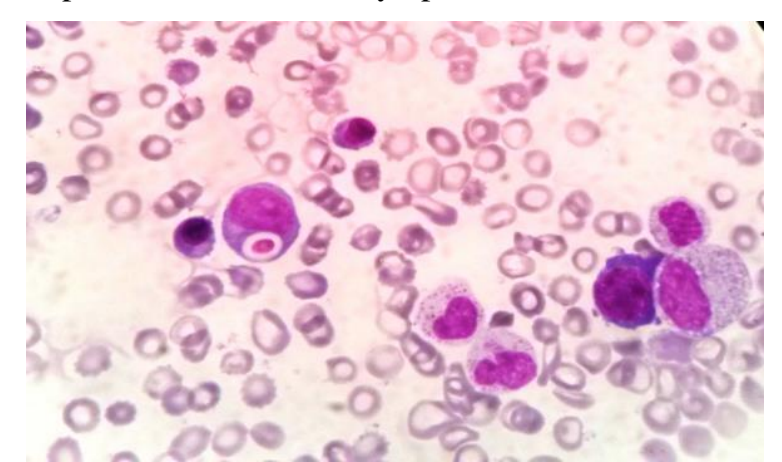

Fig. 2: The Myeloid series showing abnormal granules in their cytoplasm- Chediak Hegashi syndrome 400X magnification

\section{Clinical features and laboratory values}

Nearly most of the patients (seventeen) had fever as the presenting complaint except for one patient who had carcinoma prostate. Leucopoenia is seen in 14 cases $(83 \%)$ and out of those fourteen cases five cases had pancytopenia, nine patients had bicytopenia. Organomegaly was seen in 50\% of cases, it was either hepatosplenomegaly or splenomegaly alone. Seven cases had elevated triglyceride levels; ten cases had high LDL levels. Nine cases had elevated ferritin level. SGOT was elevated in ten cases, were as eleven cases had high SGPT. ESR was increased in thirteen cases fig.3. However, Bone marrow aspirates showed haemophagocytes in all the eighteen cases. In bone marrow biopsy some cases supported the finding in aspirate, (Fig. 4-6) but some of the biopsy was very difficult to spot.

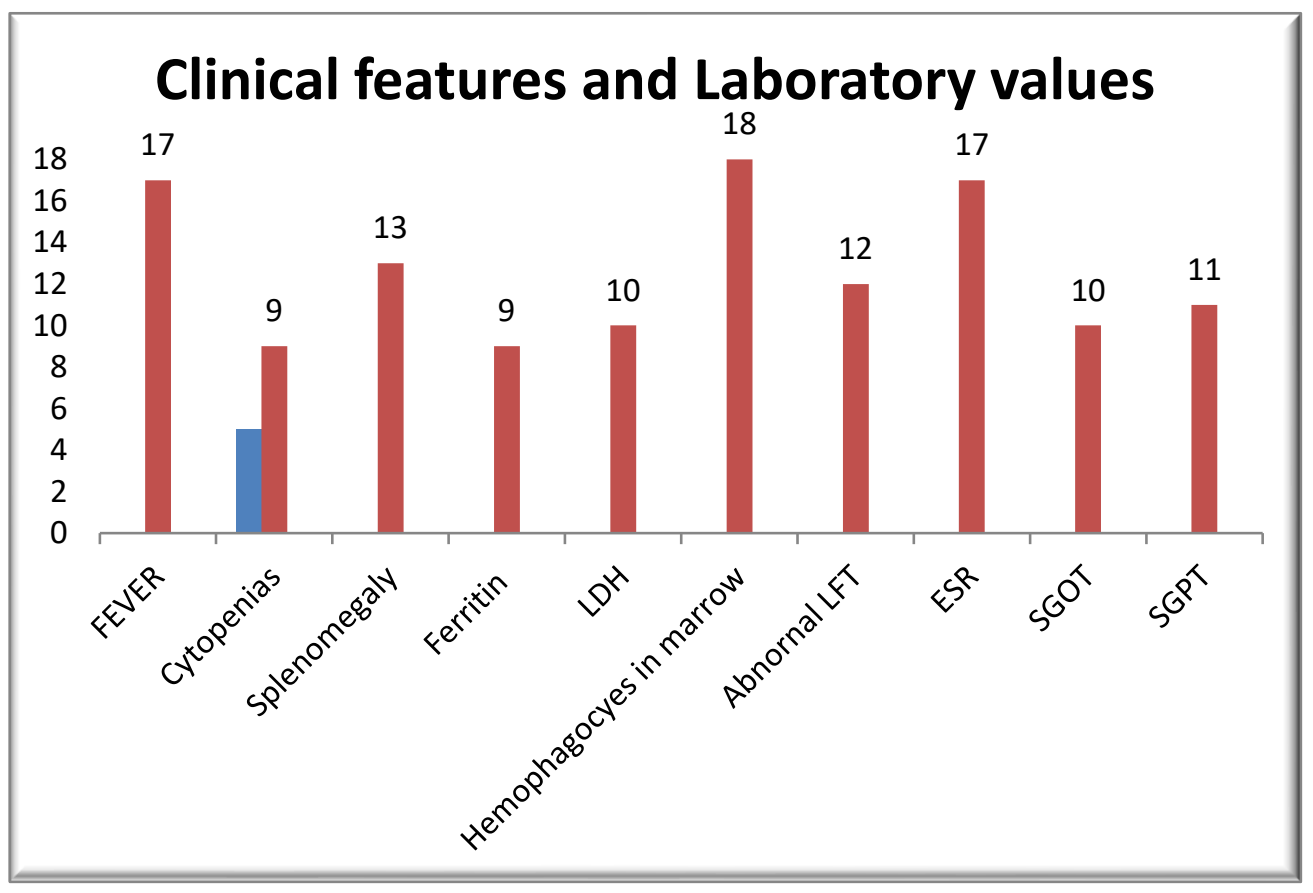

Fig. 3: Clinical features and laboratory values - Fever, Cytopenias, Splenomegaly, Ferritin, LDH-Lactose dehydrogenase, Haemophagocytes, LFT- Liver function test, ESR- Erythrocyte sedimentation Rate, SGOT- Serum glutamic oxaloacetic transaminase, SGPT- Serum Glutamic pyruvic transaminase.

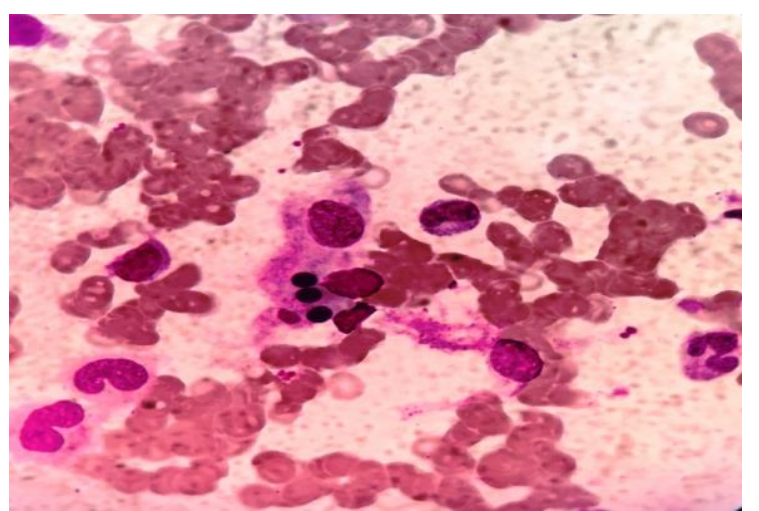

Fig. 4: Haemophagocytes in bone marrow aspiration 400X magnification 


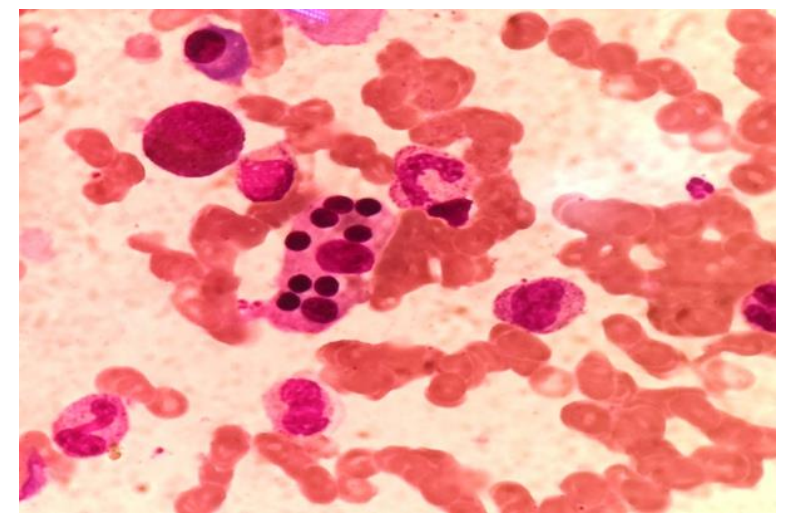

Fig. 5: Haemophagocytes in bone marrow aspiration 400X magnification

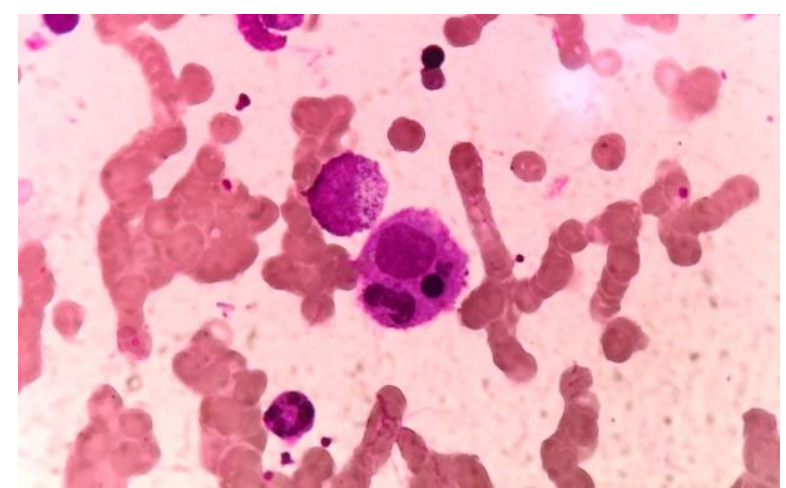

Fig. 6: Haemophagocytes in bone marrow aspiration 400X magnification

\section{DISCUSSION}

The HLH is usually diagnosed based on the HLH diagnostic criteria revised (1) by the Histiocyte Society in 2004 (HLH-2004). Five out of the following nine diagnostic criteria for HLH are to be considered for diagnosis: which includes fever, splenomegaly, cytopenia's (affecting two or more of three lineages in the peripheral blood), hypertriglyceridemia, hypofibrinogenemia, elevated ferritin, hemophagocytosis in bone marrow/spleen/lymph nodes, low or absent natural killer (NK)-cell activity, or elevated soluble CD25 (interleukin [IL]-2 receptor;) (3-6). But the patients with an established genetic abnormality (eg., FHL mutations), the diagnosis can be established without meeting the above-mentioned criteria. The 2004 diagnostic criteria for HLH does not apply to MAS (Macrophage activation syndrome) because of the overlap of clinical and laboratory findings between HLH and autoimmune diseases. Modified diagnostic criteria for MAS have been suggested by Ravelli et al., who suggested that a change in baseline laboratory findings as an indication of MAS along with the appropriate clinical symptoms $(6,7)$. In the absence of arthritis, a very high C-reactive protein, high ESR, only moderate cytopenias, reduced erythropoiesis, increased granulopoiesis with a left shift, and a high level of interleukin $1 \beta$ might suggest MAS $(6,7)$.

The tests like soluble CD25 levels and NK cell activity were not done in our institution, we considered the haemophagocytes presence in the bone marrow aspiration and biopsy along with that other criterion like fever, splenomegaly, cytopenias, triglyceride levels elevated ferritin levels and other abnormal lab values including LDH, Abnormal LFT and elevated ESR levels. None of the patients were subjected to genetic testing.

HLH usually presents with variable clinical features, but most of the patients presented with high fever, organomegaly, cytopenias, hemophagocytosis in various organs including bone marrow, spleen, liver and lymphnodes, coagulation abnormalities and some time they present with multiple organ failure or shock. It is considered that the clinical features are due to hypercytokinemia that releases proinflammatory cytokines, such as tumour necrosis factor (TNF)- $\alpha$, interferon (IFN)- $\gamma$, interleukin (IL)10 , IL-12, and IL-18 in large amounts by activated lymphocytes and macrophages. Though there are established diagnostic and therapeutic guidelines for hereditary HLH which have been widely accepted, the causes of secondary (also referred to as "reactive or acquired") HLH are yet to be understood (1-3, 813).

The eighteen 18 patients in the current study were thought to have HLH, includes primary and secondary form and they have varied clinical diagnosis. In our study $72 \%$ of cases belonged to paediatric age group and in literature we found other authors reported to have $42 \%$ to $68 \%$ of cases belonged to paediatric age group $(4,5,14-17)$. The clinical presentation of the underlying diseases is usually very broad, and is consistent with the results 
previously reported in the literature. In the current study, $22.2 \%$ patients had hematologic malignancy as compared to the study conducted by Tiong et al., almost half of their patients $(47.6 \%)$ were having haematological malignancy (12). Whereas study conducted by Mesilla et al., had 27\% of cases showed haematological malignancy and in there study ALL cases were predominant. In our study $44.4 \%$ patients had infectious diseases, and $22.2 \%$ patients had systemic disease like autoimmune disorders, septic shock syndrome and MAS $(4-8,12)$.

The special form of HLH developed in association with autoimmune diseases, which is termed as macrophage-activation syndrome and that was supposed to be the underlying cause in 2- 5\% of reactive HLH cases $(6,7)$. In our study $5.6 \%$ had Macrophage-activation syndrome and the systemic diseases which include SLE with Evan's syndrome and Juvenile Rheumatoid Arthritis. Most of the authors from their study states that MAS is very frequently associated with systemic diseases or auto immune diseases like systemic lupus erythematosus, systemic juvenile idiopathic arthritis and AOSD, but they can also be rarely reported to be associated with systemic vasculitis, Sjögren syndrome and systemic sclerosis (7,13-16). In our study one case of pyrexia of unknown origin turned out to be malaria infection in the bone marrow aspirate along with Haemophagocytes. According to the data only 20 patients having HLH secondary to malaria has been reported (5-7). In review of literature malaria and few other parasitic infections including toxoplasmosis, babesiosis, and strongyloidiasis have also been described to be a cause for HLH (9-11).

In our study all the cases showed haemophagocytes in the bonemarrow aspiration, the study conducted by Gupta et al., (14)58\% of cases showed haemophagocytes in bone marrow aspirate however they conclude that absence does not exclude the diagnosis of HLH. The ferritin levels were high in nine patients ie., $50 \%$ of cases. In most of the studies high ferritin levels were considered as important factor for diagnosis and prognosis. The ferritin levels usually peak more than $11,000 \mathrm{ng} / \mathrm{ml}$ at three week and their decrease in levels immediately will have a good prognosis $(4,17)$. There were cases which showed elevated ESR, Abnormal SGOT and SGPT where see in our study. The studies conducted by Parodi et al., and Gupta also shows that the ESR, Creactive proteins and abnormal liver function test and they were mostly associated with acquired HLH cases $(18,19)$.

\section{CONCLUSION}

In conclusion, here we have discussed a single centre experience with the patients presenting with haemophagocytes in bone marrow, along with supporting clinical features and laboratory values. Though a set of criteria are available for the HLH, it has a broad spectrum of aetiology and varied clinical features. The investigations like CD 25 levels and NK cell activity which are included in the diagnostic criteria are not available in most of the institutions, so a bone marrow aspiration or biopsy revealing hemophagocytes could be helpful to arrive at the diagnosis. From Pathological point of view, documenting each case presenting with haemophagocytes and looking into the factors like age, laboratory values and clinical features will be a valuable tool to come to the diagnosis and might help the clinician to come to a provisional diagnosis and can proceed with the treatment without much delay.

\section{CONFLICT OF INTEREST}

Authors declare that there is no conflict of interest in this study.

\section{REFERENCES}

1. Li, J., Wang, Q., Zheng, W., Ma, J., Zhang, W., Wang, W., et al., Hemophagocytic lymphohistiocytosis: clinical analysis of 103 adult patients. Medicine, 2014; 93(2).

2. Janka, G. E. Familial and acquired hemophagocytic lymphohistiocytosis. European Journal of Pediatrics. 2007; 166(2): 95-109.

3. Henter, J. I. Diagnostic guidelines for hemophagocytic lymphohistiocytosis. The FHL Study Group of the Histiocyte Society. Semin Oncol. 1991; 18: 29-33.

4. Allen, C. E., Yu, X., Kozinetz, C. A., McClain, K.L. Highly elevated ferritin levels and the diagnosis of hemophagocytic lymphohistiocytosis. Pediatric blood and cancer. 2008; 50(6): 1227-1235.

5. Henter, J. I., Horne, A., Aricó, M., Egeler, R. M., Filipovich, A. H., Imashuku, S., et al., HLH-2004: diagnostic and therapeutic guidelines for hemophagocytic lymphohistiocytosis. Pediatric Blood and Cancer. 2007; 48(2): 124-131.

6. Rahal, A. K., Fernandez, J., Dakhil, C. Undiagnosed systemic lupus erythematosus presenting as Hemophagocytic Lymphohistiocytosis. Case reports in rheumatology. 2015 Jul 8; 2015.

7. Ravelli, A., Grom, A. A., Behrens, E. M., Cron, R. Q. Macrophage activation syndrome as part of systemic juvenile idiopathic arthritis: diagnosis, genetics, pathophysiology and treatment. Genes \& Immunity. 2012; 13(4): 289-298.

8. Trizzino, A., Zur Stadt, U., Ueda, I., Risma, K., Janka, G., Ishii, E., et al., Genotype-phenotype study of familial haemophagocytic lymphohistiocytosis due to perforin mutations. Journal of Medical Genetics. 2008; 45(1): 15-21.

9. Muthu, V., Dhooria, S., Sehgal, I. S., Agarwal, R., Behera, D., Varma, N. Malaria-associated secondary haemophagocytic lymphohistiocytosis: Report of two cases $\&$ a review of literature. The Indian Journal of Medical Research. 2017; 145(3): 399.

10. Rouphael, N. G., Talati, N. J., Vaughan, C., Cunningham, K., Moreira, R., Gould, C. Infections associated with haemophagocytic syndrome. The Lancet infectious diseases. 2007; 7(12): 814-822.

11. Sung, P. S., Kim, I. H., Lee, J. H., Park, J. W. Hemophagocytic lymphohistiocytosis (HLH) associated with plasmodium vivax infection: case report and review of the literature. Chonnam Medical Journal. 2011; 47(3): 173176.

12. Tiong, I. S., Lau, M. B. Y., Toumoua, S., Chiruka, S. A case of hemophagocytic Lymphohistiocytosis in a patient with chronic lymphocytic leukemia after treatment with fludarabine, cyclophosphamide, and rituximab chemotherapy, with autopsy findings. Case Reports in 
Hematology. 2012; 2012: 326053. doi:10.1155/2012/3260 53.

13. Weitzman, S. Approach to hemophagocytic syndromes. Hematology, 2011; (1):178-183.

14. Gupta, A., Weitzman, S., Abdelhaleem, M. The role of hemophagocytosis in bone marrow aspirates in the diagnosis of hemophagocytic lymphohistiocytosis. Pediatric Blood and Cancer. 2008; 50(2): 192-194.

15. Rajagopala, S., Singh, N. Diagnosing and treating hemophagocytic lymphohistiocytosis in the tropics: systematic review from the Indian subcontinent. Acta Medica Academica. 2012; 41(2): 161-174.

16. George, M. R. Hemophagocytic lymphohistiocytosis: review of etiologies and management. Journal of Blood Medicine. 2014; 5: 69.

17. Lin, T. F., Ferlic-Stark, L. L., Allen, C. E., Kozinetz, C. A., McClain, K. L. Rate of decline of ferritin in patients with hemophagocytic lymphohistiocytosis as a prognostic variable for mortality. Pediatric Blood and Cancer. 2011; 56(1): 154-155.

18. Parodi, A., Davì, S., Pringe, A. B., Pistorio, A., Ruperto, N., Magni-Manzoni, S., et al., Macrophage activation syndrome in juvenile systemic lupus erythematosus: a multinational multicenter study of thirty-eight patients. Arthritis \& Rheumatism: Official Journal of the American College of Rheumatology. 2009; 60(11): 3388-3399.

19. Gupta, D., Mohanty, S., Thakral, D., Bagga, A., Wig, N., Mitra, D.K. Unusual association of hemophagocytic lymphohistiocytosis in systemic lupus erythematosus: cases reported at tertiary care center. The American Journal of Case Reports. 2016; 17: 739. 